\title{
Synthesis of novel boronic acid-decorated poly(2-oxazoline)s showing triple-stimuli responsive behavior
}

Gertjan Vancoillie, ${ }^{\mathrm{a}, \mathrm{b}}$ William L.A. Brooks, ${ }^{\mathrm{b}}$ Maarten A. Mees, ${ }^{a}$ Brent S. Sumerlin, ${ }^{\mathrm{b}}$ Richard Hoogenboom ${ }^{\mathrm{a}, *}$

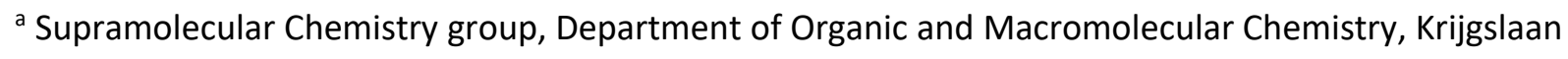
281 S4, 9000 Ghent, Belgium, richard.hoogenboom@ugent.be

${ }^{\mathrm{b}}$ George \& Josephine Butler Polymer Research Laboratory, Center for Macromolecular Science \& Engineering, Department of Chemistry, University of Florida, Gainesville, Florida 32611-7200, USA 


\section{Abstract}

Boronic acid-functionalized (co)polymers have gained increasing attention in the field of responsive polymers and polymeric materials due to their unique characteristics and responsiveness towards both changes in $\mathrm{pH}$ and sugar concentrations. This makes these (co)polymers excellently suited for various applications including responsive membranes, drug delivery applications and sensor materials. Unfortunately, boronic acid-based polymer research is also notorious for its challenging monomer synthesis and polymerization and its overall difficult polymer purification and manipulation. In light of this, many research groups have focused their attention on the optimization of various polymerization techniques in order to expand the field of BA-research including previously unexplored monomers and polymerization techniques. In this paper, a new post-polymerization modification methodology was developed allowing for the synthesis of novel boronic acid-decorated poly(2-alkyl-2-oxazoline) (PAOx) copolymers, utilizing the recently published PAOx methyl ester reaction platform. The developed synthetic pathway provides a straightforward method for the introduction of $\mathrm{pH}$ - and glucoseresponsiveness, adding this to the already wide variety of possible responsive PAOx-based systems. The synthesized BA-decorated PAOx are based on the thermoresponsive poly(2-n-propyl-2-oxazoline) (PnPropOx). This introduces a $\mathrm{pH}$ and glucose dependence on both cloud and clearance point temperatures of the copolymer in aqueous and pH-buffered conditions, yielding a triply-responsive (co)polymer that highlights the wide variety of obtainable properties using this pathway. 


\section{Introduction}

For the last 20 years, the field of responsive polymers has attracted a lot of attention. A responsive polymer can be defined as a polymer that changes its properties in response to a change in environmental conditions. ${ }^{1-3}$ Within this field, boronic acid-containing copolymers have been used for various applications based on their responsiveness towards changes in $\mathrm{pH}$ and the concentration of 1,2- and 1,3-diols. The interaction of the boronic acid functional groups with various mono-, di- and polysaccharides causes a shift in the boronic acid equilibrium to the charged anionic boronate esters. This shift increases the amount of negatively charged side chains and, therefore, the hydrophilicity of the entire (co)polymer. ${ }^{4-6}$ Depending on the architecture and structure of the copolymer in solution, this interaction can lead to the swelling of cross-linked materials, but also to complete dissolution of insoluble polymers or polymer aggregates, using a so-called isothermal LCST phase transition. ${ }^{7}$

Although some applications like affinity chromatography ${ }^{8}$ or reactive surfaces ${ }^{9}$ focus on the specific interaction between BA moieties and a chosen diol, most applications are directed towards the use of the $\mathrm{pH}$ - and saccharide-dependent polymeric phase transition in e.g., responsive membranes, drug delivery and sensor applications. The applicability of BA-containing copolymers has recently been highlighted by Sumerlin et al. ${ }^{10}$ and the different applications have been the subject of multiple reviews. ${ }^{11-13}$

The polymerization of unprotected boronic acid-containing monomers is notoriously difficult due to the low solubility of the monomers, cross-linking through boronic anhydride formation, interference of the BA moiety with the polymerization kinetics and difficulties in characterization of the obtained materials. ${ }^{14-17}$ The most popular strategy to overcome these drawbacks is to protect the boronic acid as an ester (often with pinacol), albeit at the cost of introducing two addition steps for protection of the monomer and deprotection of the resulting polymer. ${ }^{14,18-21}$

Another strategy to bypass the adverse effects of the BA moiety during polymerization and polymer characterization is to introduce these moieties through post-polymerization modifications on a 
precursor copolymer. This is most commonly achieved through the coupling of a carboxylic acidfunctionalized copolymer and an amino-functionalized BA-containing reagent like aminophenylboronic acid, activated by a carbodiimide like dicyclohexylcarbodiimide (DCC), ${ }^{8} 1$-ethyl-3(3-dimethylaminopropyl)carbodiimide (EDC) or $N, N^{\prime}$-diisopropylcarbodiimide (DIC). ${ }^{22}$ This approach has been used to modify polyacrylic acid-based polymer films, ${ }^{23}$ natural polysaccharides like alginate ${ }^{24}$ and peptides including poly(aspartic acid). ${ }^{25}$ The inverse reaction is also perfectly possible for the functionalization of amine-functionalized (co)polymers with e.g., carboxyphenylboronic. ${ }^{22,26}$ Other post-polymerization modification approaches that have been utilized to introduce BA moieties include reductive amination, ${ }^{27,28}$ radical thiol-ene coupling ${ }^{29}$ and the transformation of pendant trimethylsilane-styrene moieties into various boronic acids and esters through an exchange reaction with $\mathrm{BBr}_{3}$ and suitable alkoxide derivatives. ${ }^{30-33}$

PAOx are an interesting class of biocompatible ${ }^{34,35}$ and highly versatile polymers ${ }^{36,37}$ that allow for finetuning of various properties, including phase transition temperatures and functionalities through careful monomer design. 2-Oxazoline monomers are polymerized using cationic ring-opening polymerization (CROP), in recent years most often under microwave conditions. ${ }^{38}$ The chemical versatility allows the synthesis of well-defined PAOx (co)polymers with a large variety of side chains as well as both $\alpha$ - and $\omega$-end-groups through the choice of, respectively, initiator and terminator. ${ }^{39}$ This polymerization method, however, requires meticulous purification of all chemicals involved and restricts the range of side-chain functionalities to non-nucleophilic groups. The direct incorporation of alcohols, amines or carboxylic acids is impossible through copolymerization of corresponding unprotected functionalized monomers, as these functionalities will act as a terminator for the CROP. These functional groups can however be incorporated in the side chain of PAOx through various protection or post-polymerization modification techniques. ${ }^{40-46}$ Recently, we introduced a more general approach to introduce side chain functional groups through direct amidation of a labile methyl ester-side chain (co)polymer ${ }^{47}$ Currently, there is no scientific publication available that details a pathway for the synthesis of BA-containing PAOx, nor for the synthesis of a BA-containing 2-oxazoline 
monomer, either protected or unprotected. The interference between the BA moiety and the labile oxazoline species, but also the possible interactions with the cationic oxazolinium species during polymerization, most likely has discouraged most groups in attempting the combination of these two chemistries. This combination is however very promising as it allows the introduction of $\mathrm{pH}$ and sugar responsive behavior in the biocompatible PAOx.

In this paper, we will use the previously mentioned methyl ester PAOx platform to incorporate the incompatible BA moieties and synthesize novel BA- decorated PAOx. To highlight the large variety of possible polymeric properties, the introduced $\mathrm{pH}$ - and glucose-responsive behavior will be combined with temperature-responsive phase separation through the incorporation of BA-containing side chains with poly(2-n-propyl-2-oxazoline) (PnPropOx), which exhibits LCST-like behavior around $25^{\circ} \mathrm{C} .{ }^{48-51}$

\section{Experimental}

\section{Chemicals}

$n$-Propyloxazoline (nPropOx) was synthesized according to a literature procedure, ${ }^{52}$ purified and dried by fractional distillation over $\mathrm{BaO}$. Methyl ester oxazoline was synthesized and purified according to a previously reported procedure..$^{53}$ 4-CPBA (> 97\%) was purchased from Accela ChemBio Inc, HATU (99\%) from Iris Biotech, ethylenediamine (99\%), D-(+)-glucose ( $\geq 99.5 \%)$ and disopropylethylamine (DIPEA, 99.5\%) from Sigma-Aldrich and finally sodium hydroxide (extra pure, micropearls) from Acros Organics. HPLC grade solvents diethyl ether and DCM were obtained from Sigma Aldrich, dimethylformamide (DMF, peptide synthesis grade) from Biosolve. TFA (99\%) was purchased from Alfa-Aeser. All deuterated solvents were bought from Cambridge Isotope Laboratories. Dialysis was performed with Spectrum Labs regenerated-cellulose membranes with 3000 Da molecular weight cut-off. Molecular sieves (4Å) were bought from VWR and activated by heating at $160^{\circ} \mathrm{C}$ for $24 \mathrm{~h}$ prior to use.

\section{Instruments}

SEC was performed on an Agilent 1260-series HPLC system equipped with a 1260 online degasser, a 1260 ISO-pump, a 1260 automatic liquid sampler, a thermostatted column compartment, a 1260 diode 
array detector (DAD) and a 1260 refractive index detector (RID). N,N-Dimethylacetamide (DMAc) containing $50 \mathrm{mM}$ of $\mathrm{LiCl}$ was used as eluent at a flow rate of $0.593 \mathrm{~mL} / \mathrm{min}$. The spectra were analyzed using the Agilent Chemstation software with GPC add-on. Molar mass and $\oslash$ values were calculated against Varian PS or PMMA standards. ${ }^{1} \mathrm{H}-\mathrm{NMR}$ spectra were recorded on a Bruker Avance $300 \mathrm{MHz}$ or $500 \mathrm{MHz}$ spectrometer at room temperature or an Inova $500 \mathrm{MHz}$ spectrometer. The chemical shifts are given relative to tetramethylsilane (TMS). Deionized water was prepared with a resistivity less than 18.2 $\mathrm{M} \Omega \times \mathrm{cm}$ using an Arium 611 from Sartorius with the Sartopore $2150(0.45+0.2 \mu \mathrm{m}$ pore size $)$ cartridge filter. pH-values were measured using a Consort C561 equipped with a universal pH electrode with build in temperature probe. Turbidimetry measurements were performed using an Avantium Crystal16 parallel crystallizer.

\section{Synthesis of mono-boc protected ethylene diamine}

$31 \mathrm{~mL}$ of ethylene diamine $(0.46 \mathrm{~mol}, 10.66 \mathrm{eq})$ was mixed with $200 \mathrm{~mL}$ of 1,4-dioxane and stirred vigorously. A mixture of $10 \mathrm{~mL}$ boc-anhydride (0.044 mol, 1 eq) in $200 \mathrm{~mL}$ 1,4-dioxane was added drop wise over several hours at rt. After $48 \mathrm{~h}$ the mixture was decanted, filtered and evaporated to yield an oily residue. This was added to $250 \mathrm{~mL}$ of deionized water to precipitate the double reacted symmetrical side product. After filtration, the aqueous phase was saturated with $\mathrm{NaCl}(\approx 90 \mathrm{~g})$ and extracted with DCM $(6 \times 100 \mathrm{~mL})$. The collected organic phases were dried with anhydrous $\mathrm{Na}_{2} \mathrm{SO}_{4}$ and afterwards the solvent was evaporated to yield a yellowish oil. Yield: $6.63 \mathrm{~g}(95 \%) .{ }^{1} \mathbf{H}-\mathbf{N M R}\left(\mathbf{C D C l}_{3}\right.$, $500 \mathrm{MHz}): \delta(\mathrm{ppm}) 3.12\left(\mathrm{~d}, \mathrm{~J}=5.5 \mathrm{~Hz}, 2 \mathrm{H},-\mathrm{CO}-\mathrm{NH}-\mathrm{CH}_{2}-\mathrm{CH}_{2}-\right), 2.75\left(\mathrm{t}, \mathrm{J}=5.9 \mathrm{~Hz}, 2 \mathrm{H},-\mathrm{CH}_{2}-\mathrm{CH}_{2}-\mathrm{NH}_{2}\right), 1.40$ $\left(\mathrm{s}, 9 \mathrm{H},\left(\mathrm{CH}_{3}\right)_{3}-\mathrm{C}-\mathrm{O}-\mathrm{CO}-\right)$.

\section{Synthesis of 4-carboxyphenylboronic pinacol ester (4-CPBA-pin)}

$3.04 \mathrm{~g}$ of pinacol (25.7 mmol, $0.95 \mathrm{eq}$ ) was dissolved in $100 \mathrm{~mL}$ of anhydrous DCM. To this mixture, $12 \mathrm{~g}$ of dried activated molecular sieves $(4 \AA)$ and $4.5 \mathrm{~g}$ of 4 -CPBA $(27.1 \mathrm{mmol}, 1 \mathrm{eq})$ were added. This mixture was stirred for $12 \mathrm{~h}$ at rt after which the unreacted 4-CPBA and the molecular sieves were filtered off. The resulting white solid, after evaporation to dryness, was recrystallized from hot ethyl acetate to yield the product as white, needle like crystals. Yield: $3.09 \mathrm{~g}(48.4 \%) .{ }^{1} \mathrm{H}-\mathrm{NMR}\left(\mathrm{CDCl}_{3}\right.$, 
$500 \mathrm{MHz}) \delta(\mathrm{ppm}) 8.13\left(\mathrm{~d}, \mathrm{~J}=8.3 \mathrm{~Hz}, 2 \mathrm{H}, \mathrm{HOOC}-(\mathrm{CH})_{2}-\right), 7.93\left(\mathrm{~d}, \mathrm{~J}=8.2 \mathrm{~Hz}, 2 \mathrm{H},-(\mathrm{CH})_{2}-\mathrm{B}\right), 1.39(\mathrm{~s}, 12 \mathrm{H}$, $\left.\mathrm{O}-\left(\mathrm{C}\left(\mathrm{CH}_{3}\right)_{2}\right)_{2}\right)$.

\section{Copolymerization of n-PropOx and MestOx}

The starting copolymers are synthesized via microwave-assisted cationic ring opening polymerization, according to a previously reported procedure. ${ }^{54}$ The monomers and the initiator methyl tosylate (MeOTs) were dissolved in dry acetonitrile $\left([\mathrm{M}]_{\text {tot }}=3 \mathrm{M}\right.$ ) with a monomer to initiator ratio of $100 / 1$. The polymerization mixture was heated to $140{ }^{\circ} \mathrm{C}$ for 20 min using microwave irradiation after which the polymerization was terminated at high conversions by the addition of piperidine. The copolymers were purified by double precipitation in diethyl ether from DCM and dried in a vacuum oven after which they were characterized using ${ }^{1} \mathrm{H}-\mathrm{NMR}$ spectroscopy and SEC. Two different copolymers were synthesized differing in the feed ratio between the comonomers, containing either 10 or 20 mol\% of MestOx as confirmed using ${ }^{1} \mathrm{H}-\mathrm{NMR}$ spectroscopy.

\section{Direct amidation of $\mathrm{P}(\mathrm{nPropOx}-\mathrm{co}-\mathrm{MestOx})$}

A typical procedure for this reaction will be described for $\mathrm{P}\left(\mathrm{nPropO} \mathrm{x}_{80}-\mathrm{Co}^{-} \mathrm{MestO}_{20}\right) .0 .5 \mathrm{~g}$ of $\mathrm{P}\left(\mathrm{nPropO} \mathrm{x}_{80}\right.$-co-MestOx 20$)(12.3 \mathrm{kDa}, 0.813 \mathrm{mmol}$ methyl esters, $1 \mathrm{eq})$ was dissolved in $2 \mathrm{~mL}$ of monoboc-protected ethylene diamine $(12.2 \mathrm{mmol}, 15 \mathrm{eq})$ and a few drops of DCM to increase the solubility and decrease the viscosity. This mixture was stirred for 3 days at $\mathrm{rt}$ and monitored using ${ }^{1} \mathrm{H}-\mathrm{NMR}$ spectroscopy focusing on the disappearance of the methyl ester peak $(\delta=3.68 \mathrm{ppm})$. After complete conversion, the polymer was precipitated in a ten-fold excess volume of cold diethyl ether, decanted and dried. Subsequently, the boc-group was removed by dissolving the PAOx in $20 \mathrm{~mL}$ of $1 / 1$ TFA/DCM at $\mathrm{rt}$ and stirred for $12 \mathrm{~h}$. After evaporation of the TFA/DCM, the polymer was redissolved in deionized water and dialyzed against deionized water for three days, changing the water twice a day. Freezedrying of the purified polymer solution revealed a white fluffy material. Yield: $0.32 \mathrm{~g}(68.14 \%)$, SEC

(DMAc + 50mM LiCl, PMMA-std): Mn = 21,000 g/mol, $Đ=1.08,{ }^{1} \mathrm{H}-\mathrm{NMR}$ spectroscopy (500MHz, $\left.\mathrm{CDCl}_{3}\right): \delta(\mathrm{ppm}) 3.4$ (broad, backbone), 2.3 (broad, $\mathrm{N}-\mathrm{CO}-\mathrm{CH}_{2}-$ ), 1.55 (broad, $\mathrm{CO}-\mathrm{CH}_{2}-\mathrm{CH}_{2}-\mathrm{CH}_{3}$ ), 0.85 (broad, $\mathrm{CO}-\mathrm{CH}_{2}-\mathrm{CH}_{2}-\mathrm{CH}_{3}$ ). Based on the similar chemical environment, the CO-NH-CH$-\mathrm{CH}_{2}-\mathrm{NH}_{2}$ most 
likely overlaps with the backbone proton signal while the $\mathrm{CO}-\mathrm{NH}-\mathrm{CH}_{2}-\mathrm{CH}_{2}-\mathrm{NH}_{2}$ overlaps with the peaks of the first $\mathrm{CH}_{2}$ group of the nPropOx side chains. The amide proton $(8.0 \mathrm{ppm})$ and amine protons (6.0 ppm) are visible but very broad and irreproducible due to proton exchange with residual water. A small signal of the methyl group at the $\alpha$-end $(3.0 \mathrm{ppm})$ and the piperidine at the $\omega$-end $(3.12 \mathrm{ppm})$ are noticeable although not accurately integratable.

Functionalization of $\mathrm{P}(\mathrm{nPropOx}-\mathrm{co}-\mathrm{AmOx})$ with boronic acid moieties through HATU coupling A typical procedure for this reaction will be described for $\mathrm{P}\left(\mathrm{nPropO}_{80}-\mathrm{CO}^{-}-\mathrm{AmOx}_{20}\right) .0 .3 \mathrm{~g}$ of $\mathrm{P}\left(\mathrm{nPropO} \mathrm{x}_{80}\right.$-Co-MestOx 20$)(12.9 \mathrm{kDa}, 0.48 \mathrm{mmol}$ amine, 1 eq) was dissolved in $1.5 \mathrm{~mL}$ of DMF. Separately, $0.124 \mathrm{~g}$ of 4-CPBA-pin $(0.5 \mathrm{mmol}, 1.1 \mathrm{eq})$ and $0.25 \mathrm{~g}$ of HATU $(0.66 \mathrm{mmol}, 1.4 \mathrm{eq})$ were dissolved in $1.5 \mathrm{~mL}$ of DMF and $0.43 \mathrm{~mL}$ diisopropylethylamine (DIPEA, $2.47 \mathrm{mmol}, 5.3 \mathrm{eq}$ ). This was stirred for $30 \mathrm{~min}$ at $\mathrm{rt}$ until the mixture turned dark yellow. The reaction mixture was added to the polymer solution and stirred for another $24 \mathrm{~h}$ at $\mathrm{rt}$. The polymer was precipitated once in a ten-fold excess volume of cold diethyl ether, decanted and dried. Subsequently, the pinacol group was removed by dissolving the polymer in $\mathrm{NaOH}$ aqueous solution $(\mathrm{pH}$ 10) and dialyzing against a basic aqueous solution $(\mathrm{NaOH}, \mathrm{pH}$ 10) for three days, changing the water twice a day. The sample was then neutralized by dialysis against deionized water for three days, changing the water twice a day. Freezedrying yielded a white, fluffy polymer. Yield: $0.20 \mathrm{~g}$ (55 \%), SEC (DMAc + 50mM LiCl, PMMA-std): Mn $=29,000 \mathrm{~g} / \mathrm{mol}, \mathrm{D}=1.13,{ }^{1} \mathrm{H}-\mathrm{NMR}$ spectroscopy (500MHz, MeOD): $\delta(\mathrm{ppm}) 7.65$ (broad, aromatic), 3.4 (broad, backbone), 2.3 (broad, N-CO-CH- ), 1.5 (broad, $\mathrm{CO}-\mathrm{CH}_{2}-\mathrm{CH}_{2}-\mathrm{CH}_{3}$ ) 0.75 (broad, $\mathrm{CO}-\mathrm{CH}_{2}-\mathrm{CH}_{2}-\mathrm{CH}_{3}$ ). Based on the similar chemical environment, the $\mathrm{CO}-\mathrm{NH}_{-} \mathrm{CH}_{2}-\mathrm{CH}_{2}-\mathrm{NH}-\mathrm{CO}$ most likely overlaps with the backbone proton signal. Further elucidation of the large, multimodal peak at $3.4 \mathrm{ppm}$ is obscured due to interference with $\mathrm{MeOH}$ (3.33 ppm) and residual 1,4-dioxane (3.6 ppm).

\section{Turbidimetry measurements - Crystal 16}

Cloud point measurements on the PAOx copolymers were performed in $0.7 \mathrm{~mL}$ solutions containing $1 \mathrm{mg} / \mathrm{mL}$ of polymer in deionized water. Temperature ramps of $1{ }^{\circ} \mathrm{C} / \mathrm{min}$ were used to heat and cool between 5 and $95{ }^{\circ} \mathrm{C}$ while stirring at 700 RPM and flushing the measurement chamber with 
pressurized air to reduce condensation on the cuvette at low temperatures. Three heating and three cooling ramps were performed alternately. The $T_{c p}$ and $T_{c l}$ were determined at $50 \%$ transmission and averaged over the final two cycles.

\section{Results \& discussion}

Synthesis of boronic acid-decorated poly(2-oxazoline)s through post-polymerization modification

The cationic ring opening polymerization (CROP) of 2-oxazolines to prepare PAOx does not allow the direct incorporation of nucleophilic side chains such as alcohols, amines or carboxylic acids. These nucleophilic functionalities will act as a terminator for the CROP resulting in loss of control over the polymerization. Alternatively, these groups can be incorporated through various protection or postpolymerization modification techniques using, for example, a (co)polymer with labile methyl ester-side chains. ${ }^{47}$ Based on this methyl ester PAOx platform and its direct amidation, a novel pathway has been developed to synthesize novel PAOx copolymers with BA moieties in the side chain (Figure 1).

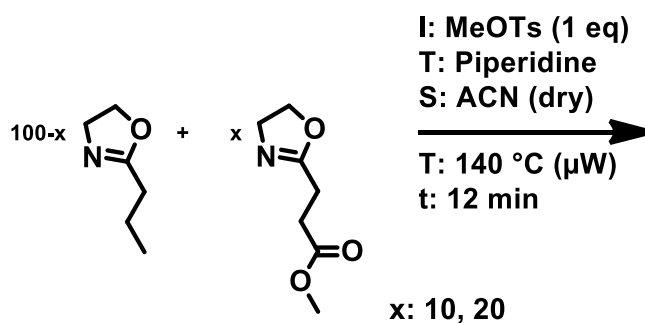

nPropox MestOx

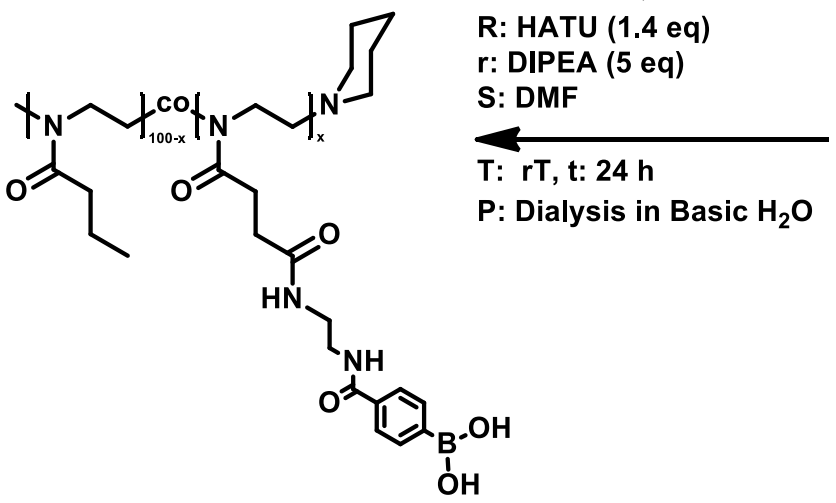<smiles>CCCC(=O)N(C)CCC(C)(C)N(C)CCN1CCCC1</smiles>

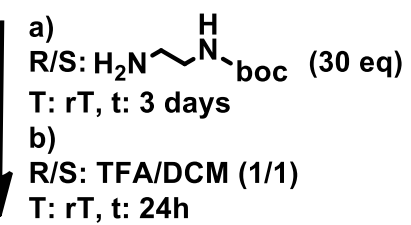<smiles>CCCC(=O)N(C)C[14CH2][14CH](C)[14C](=O)N(CCN1CCCC1)C(=O)CCC(=O)NCN</smiles>

Figure 1. Overall reaction scheme for the post-polymerization modification of $\mathrm{P}(\mathrm{nPropOx}$-co-MestOx) to introduce $\mathrm{BA}$ moieties in the side chains 
The methyl ester copolymer is synthesized by CROP of 2-n-propyl-2-oxazoline (nPropOx) and 2methoxycarbonylethyl-2-oxazoline (MestOx) in acetonitrile through microwave-assisted polymerization initiated by methyltosylate (MeOTs) and stopped after $12 \mathrm{~min}$ at $140^{\circ} \mathrm{C}$ by the removal of heat and addition of piperidine as terminator. The ratio of monomer to initiator was kept at 100/1 while the content of MestOx in the feed ratio was either 10 or $20 \%$. The resulting statistical copolymers were purified by two precipitations in cold diethylether. ${ }^{53,54}$

The methyl ester side chain of the $\mathrm{P}\left(\mathrm{nPropOx}-\mathrm{Co}_{\mathrm{M}} \mathrm{MestOx}\right)$ can easily be modified via a direct amidation reaction with various primary amines. ${ }^{47}$ This one step procedure is most efficient with small, liquid amines in which the (co)polymer can be dissolved. Under these conditions of high polymer concentration and large amine excess, the direct amidation can quantitatively be performed at room temperature. ${ }^{47}$ To prevent any polymer cross-linking during this step, mono-boc-protected ethylene diamine (boc-EDA) was used as direct amidation reagent and synthesized by reacting boc-anhydride with ethylenediamine. The formation of mono-boc-protected ethylene diamine was favored by working under dilute conditions in DCM and by slowly adding the boc-anhydride solution to a large excess of ethylene diamine while cooling. After evaporation of the organic solvent, the mono-bocprotected ethylene diamine was isolated by extraction with EtOAc from a $\mathrm{NaCl}$ saturated aqueous solution. Any remaining, unreacted ethylene diamine remained water-soluble, while double bocprotected ethylene diamine precipitated in the aqueous solution and was filtered off prior to $\mathrm{NaCl}$ addition. The salt decreased the solubility of the desired boc-EDA compound by increasing the ionic strength of the solvent. The direct amidation was then performed by solubilizing $\mathrm{P}(\mathrm{nPropOx}-\mathrm{co}-$ MestOx) into the viscous boc-EDA and stirring at $\mathrm{rt}$ for 3 days. The reaction was easily followed by ${ }^{1} \mathrm{H}-$ NMR spectroscopy (Figure 2), focusing on the disappearance of the methyl ester peak at $3.6 \mathrm{ppm}$ $\left(\mathrm{CDCl}_{3}\right)$. After precipitation of the copolymer in cold diethyl ether, the boc-groups of the side chains were removed in $1 / 1$ TFA/DCM, after which any remaining ethylenediamine was removed via dialysis against deionized water. The copolymer was finally obtained by freeze-drying of the mixture to yield a white, brittle material which was highly hygroscopic. Even though the use of mono-boc-protected 
ethylenediamine completely prevents any cross-linking during the amidation reaction, it has been reported that potential cross-linking becomes a bigger issue for copolymers containing more than $20 \%$ MestOx..$^{55}$ This means that for the currently used starting copolymers, the first side-chain modification step can also be performed using a large excess of unprotected EDA. This would not only remove the extra protection and deprotection steps but also simplifies the copolymer work-up to evaporation under high vacuum and freeze-drying.

The synthesized $\mathrm{P}(\mathrm{nPropOx}-\mathrm{co}-\mathrm{AmOx})$ provided a handle for the boronic acid incorporation through amide coupling. For this amide coupling, the use of HATU was preferred since it is considered one of the more reactive coupling reagents. Prior to reaction, 4-carboxyphenylboronic acid (4-CPBA) was protected with pinacol in order to increase the solubility of the BA moiety in organic solvents and simplify both the synthesis and resulting polymer characterization by reducing the reactivity of the BA moiety. The condensation reaction between pinacol and a small excess of 4-CPBA is forced to completion by working under anhydrous conditions and removing the released water by addition of activated molecular sieves ( $4 \AA$, pre-treated at $160^{\circ} \mathrm{C}$ for $24 \mathrm{~h}$ ). The purification of this compound was facilitated by the very low solubility of 4-CPBA, allowing filtration of the added excess after complete consumption of the pinacol. If necessary, due to the presence of minor impurities, the synthesized pinacol protected 4-carboxyphenylboronic acid (4-CPBA-pin) can be recrystallized from hot EtOAc yielding white, needle like crystals. 4-CPBA-pin was activated by reacting with HATU in DMF with DIPEA by stirring for 30 min at rt. The formation of the activated ester can be visually monitored as it forms a light yellow color. This mixture was then added to a solution of $\mathrm{P}(\mathrm{nPropOx}-\mathrm{co}-\mathrm{AmOx})$ solubilized in DMF and stirred for another $24 \mathrm{~h}$ at room temperature. Finally, the polymer was purified and deprotected via dialysis against basic water and neutralized by dialysis against deionized water. After freeze drying, the $\mathrm{P}(\mathrm{nPropOx}-\mathrm{co}-\mathrm{BAOx})$ was collected as a hygroscopic, white fluffy material. Using ${ }^{1} \mathrm{H}-$ NMR spectroscopy (Figure 2), the ratio of the four phenyl protons (7.6 ppm) to the methyl group of nPropOx $(0.9 \mathrm{ppm})$ was used to calculate the percentage of incorporated BA groups to be 8.5 and $15 \%$ respectively. The difference between the calculated feed of MestOx and the eventually incorporated 
BAOx content is within the error margins for ${ }^{1} \mathrm{H}-\mathrm{NMR}$ spectroscopy but could also indicate an incomplete functionalization, although both the direct amidation ${ }^{47}$ and HATU-assisted amide coupling are known as near-quantitative reactions.
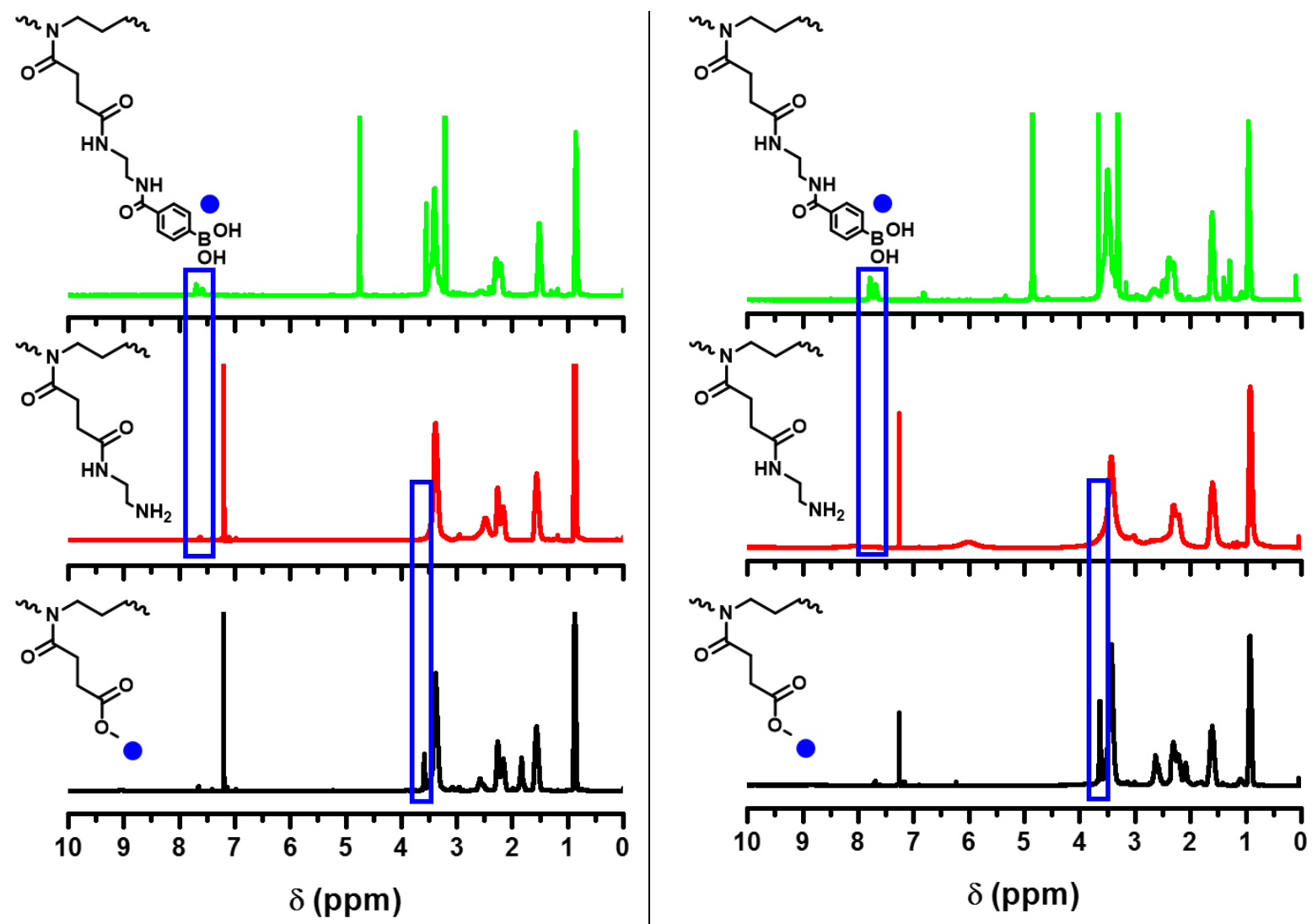

Figure 2. ${ }^{1} \mathrm{H}-\mathrm{NMR}$ spectra of the different reaction steps including $\mathrm{P}(\mathrm{nPropOx}-$ co-MestOx) (black), $\mathrm{P}(\mathrm{nPropOx}-\mathrm{co}-\mathrm{AmOx})$ (red) and $\mathrm{P}(\mathrm{nPropOx}-\mathrm{co}-\mathrm{BAOx})$ (green). Left: $10 \%$ MestOx in feed. Right: $20 \%$ MestOx in feed.

The purified, deprotected copolymers were further characterized using SEC to confirm that the modifications did not influence the molar mass dispersity or cause cross-linking. Figure 3 shows the characteristic SEC traces for $\mu \mathrm{W}$ assisted polymerization of 2-oxazolines with low molar mass dispersities $(\boxplus<1.1)$ and a double molecular weight shoulder caused by transfer reactions during the polymerization..$^{52,56}$ The retention of the polymer dispersity and modality in the SEC traces after modification suggests that no intermolecular cross-linking has taken place in the purified copolymer samples. An interesting observation is the influence of the different modification steps on the hydrodynamic volume in DMAc (+ 50mM LiCl). The SEC traces for the $20 \%$ MestOx nicely shift to higher molecular weight for each modification step, showing that with each step the SEC solvent becomes a 
'better' solvent for the modified copolymer. This trend is probably a simplification of the influences of the changing side groups, as the traces of the 10\% MestOx copolymers do not show this gradual increase despite incontrovertible proof of modification supplied by the ${ }^{1} \mathrm{H}-\mathrm{NMR}$ spectra (Figure 2). This discrepancy between the different SEC trace overviews might also be related to the presence of residual salts in the purified $\mathrm{P}\left(\mathrm{nPropO} \mathrm{x}_{90}-\mathrm{Co}-\mathrm{BAOx}_{10}\right)$.
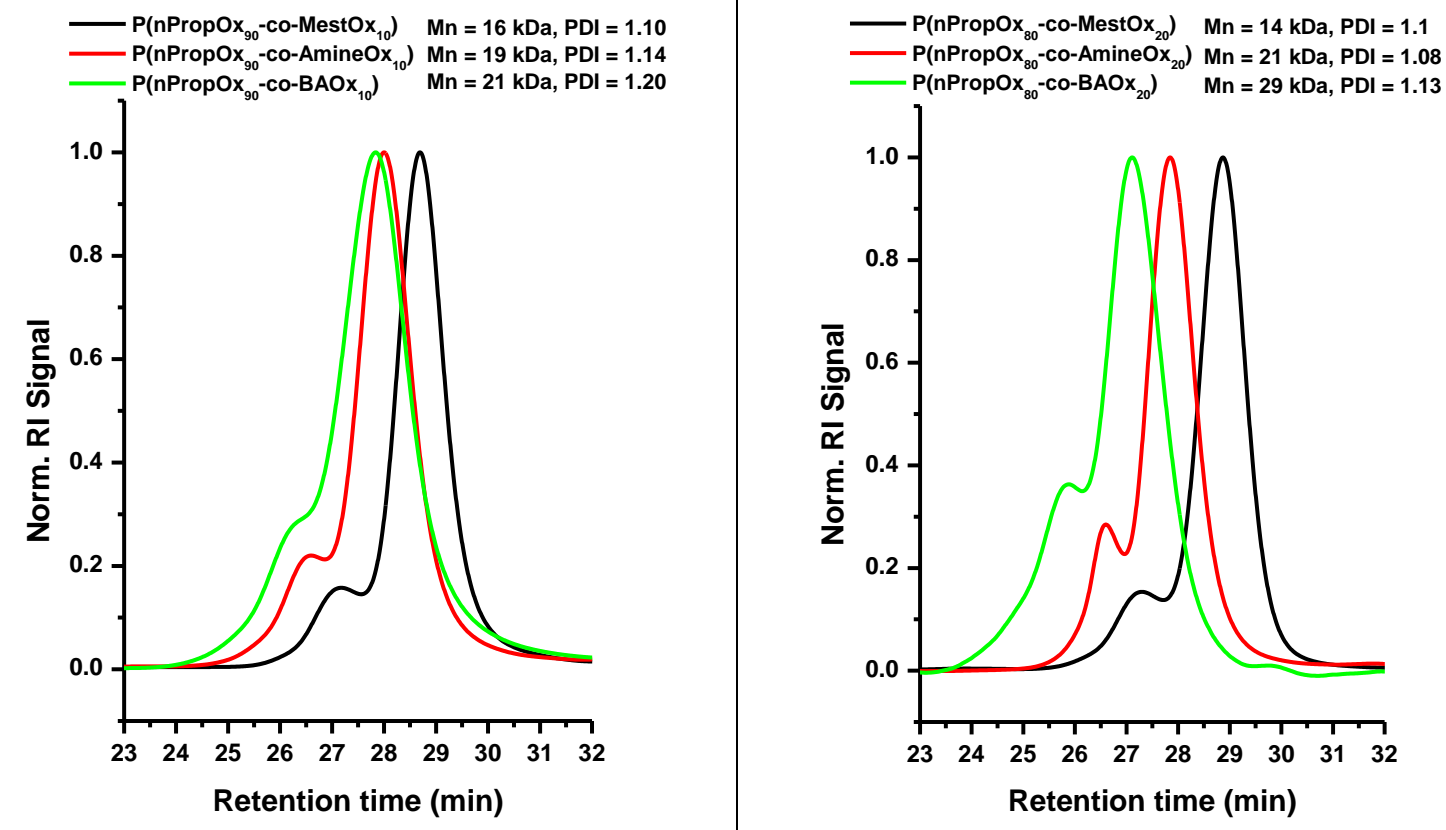

Figure 3. SEC traces of the different reaction steps including P(nPropOx-co-MestOx) (black), P(nPropOx-co-AmOx) (red) and P(nPropOx-co-BAOx) (green). Left: $10 \%$ MestOx in feed. Right: $20 \%$ MestOx in feed.

\section{$\mathrm{pH}$-dependent thermal phase transition}

$\mathrm{P}(\mathrm{nPropOx})$ is known for its thermoresponsive properties characterized by a sharp LCST transition around $25{ }^{\circ} \mathrm{C}$ without any noticeable hysteresis between the heating and the cooling curves. ${ }^{48,57}$ The incorporation of BA moieties through post-polymerization modification allows for the introduction of an additional level of control on the thermoresponsive properties through the $\mathrm{pH}$ - and glucosedependent equilibrium between neutral boronic acid and charged boronate acid/ester. The influence of $\mathrm{pH}$ on the thermoresponsive properties is determined by performing turbidimetry measurements of a $\mathrm{P}(\mathrm{nPropOx}-\mathrm{co}-\mathrm{BAOx})$ aqueous solution at different $\mathrm{pH}$. The polymer phase transition is characterized by a cloud point temperature $\left(T_{c p}\right)$ and clearance point temperature $\left(T_{c l}\right)$, which are defined as the temperature at $50 \%$ transmittance for the heating and the cooling curves, respectively. 
In general, three heating and cooling cycles were performed on a single sample with a temperature ramp of $1{ }^{\circ} \mathrm{C} / \mathrm{min}$ with the first cycle designed to remove any memory effects of the material while the other two cycles are used to calculate the average $T_{c p}$ and $T_{c l}$. The various samples at different $p H$ values were obtained starting from a completely solubilized polymer under basic conditions $(1 \mathrm{mg} / \mathrm{mL}$, $0.01 \mathrm{M} \mathrm{NaOH}$ aq.) and subsequent addition of various concentrations of $\mathrm{HCl}$ to minimize the added volume, limiting the effect of dilution on the $T_{c p}$ and $T_{c l}$. Titrating a highly basic solution ( $p H \approx 13$ ) using acids provides a consistent starting point for the titration experiments while ensuring the full solubilization of the modified copolymers as the BA moieties are now completely charged, giving the copolymer its maximum hydrophilicity. It is important to note that for all the aqueous solutions, MilliQ water was used to remove any salting-in or salting-out effects and allow for evaluation of the $\mathrm{pH}$ independently.

The results shown in Figure 4 show a very broad range of about $45 \mathrm{~K}$ of obtainable transition temperatures for the polymer with $15 \% \mathrm{BA}$ content and about $20 \mathrm{~K}$ for the polymer with $8.5 \% \mathrm{BA}$ content when $\mathrm{pH}$ is varied from 8.5 to 10.5 , during which the BA moieties transform from completely neutral to completely anionically charged species. At high $\mathrm{pH}(>10)$ the boronic acid moieties are mostly negatively charged, increasing the hydrophilicity of the copolymer and thereby increasing both $\mathrm{T}_{\mathrm{cp}}$ and $\mathrm{T}_{\mathrm{cl}}$. It appears that the transition temperatures gradually decrease with decreasing $\mathrm{pH}$ from about $\mathrm{pH}$ of 10 corresponding to the $\mathrm{pH}$-induced shift in the boronic acid equilibrium to the neutral side, decreasing the hydrophilicity of the copolymer. Beyond the S-shaped curve obtained in the $\mathrm{pH}$ range of 8.5 to 10.5 , the effect on the transition temperatures can no longer be attributed to a change in charge density on the polymer chain as it is considered to be fully neutral or fully charged respectively. Any further change in transition temperature is therefore most likely a direct result of the changing aqueous environment. This means that in the more basic range $(>10.5)$ the increased ionic strength of the aqueous solution most likely causes a salting-in effect resulting in the full solubilization $\left(T_{c p}>95^{\circ} \mathrm{C}\right.$ ) of the $15 \%$ BA copolymer while the $8.5 \%$ BA copolymer shows a rapid increase in $T_{c p}$ to 70 
${ }^{\circ} \mathrm{C}$ and also full solubilization at even higher $\mathrm{pH}$ values. In the acidic $\mathrm{pH}$ range $(<7)$ no $\mathrm{T}_{\mathrm{cp}}$ of $\mathrm{T}_{\mathrm{cl}}$ could be observed as the polymer was insoluble.

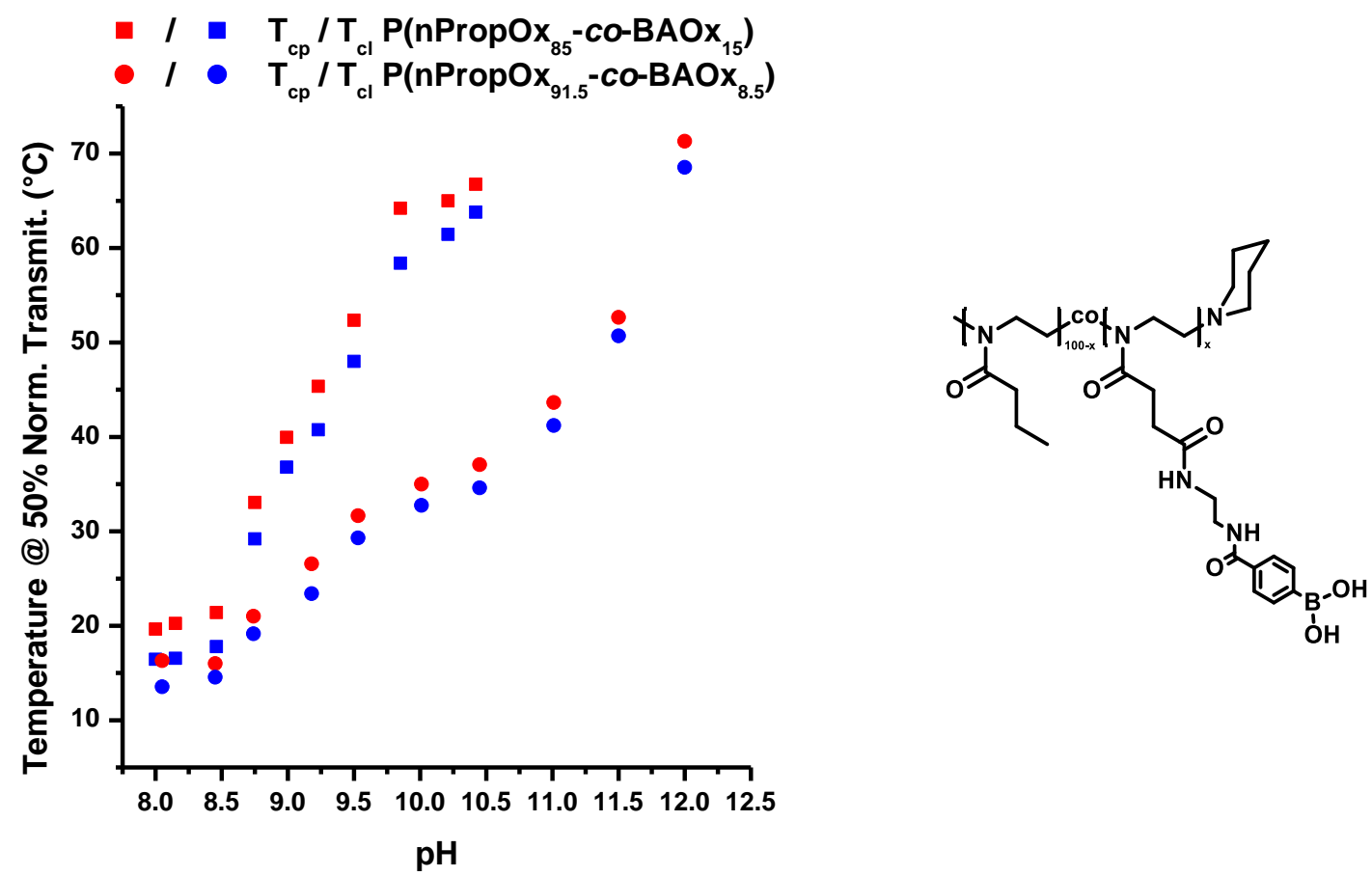

Figure 4. Left: $T_{c p}$ and $T_{c l}$ in function of $\mathrm{pH}$ for a $1 \mathrm{mg} / \mathrm{mL}$ aqueous solution of $\mathrm{P}\left(\mathrm{nPropOx}_{85}-c o-\mathrm{BAOx}_{15}\right)$. Right: Structure of the investigated $\mathrm{P}\left(\mathrm{nPropOx_{85 }}-\mathrm{co}\right.$ BAO $\left._{15}\right)$.

\section{Glucose-dependent thermal phase transition}

Due to the strong resemblance between the BA moieties incorporated into the PAOx and the previously discussed DDOPBA structure, the first attempts at investigating glucose responsivity were performed in a PBS buffer at $\mathrm{pH}$ of 7.4. Unfortunately, due to the strong salting-out effect caused by the phosphate and $\mathrm{NaCl}$ salts ${ }^{58}$ but also possible complexation interactions between the phosphates and the $\mathrm{BA}$ moieties, $\mathrm{P}(\mathrm{nPropOx}-\mathrm{CO}-\mathrm{BAOx})$ is insoluble under these conditions regardless of temperature or glucose concentration. To bypass this problem and provide a proof of concept for glucose responsiveness, a polymer solution was buffered at the beginning of the $\mathrm{pH}$ induced temperature ramp (Figure 4), or more specifically at a pH of 8.6, using a $0.1 \mathrm{M} \mathrm{HEPES}$ solution to allow maximum sensitivity towards $\mathrm{D}$-glucose. The screening of the glucose-dependent thermal phase transition was then performed by titrating small quantities of a highly concentrated D-glucose solution made with the same $0.1 \mathrm{M} \mathrm{HEPES}$ buffer solution to not dilute the polymer solution and keep the pH constant. 
The results in Figure 5 show the expected increase in transition temperatures with increasing concentration of D-Glu caused by the formation of charged boronate esters. Although the temperature window is slightly smaller compared to the one observed during $\mathrm{pH}$ titration in both cases, the $35 \mathrm{~K}$ difference in the case of $\mathrm{P}\left(\mathrm{nPropO} \mathrm{x}_{85}-\mathrm{co}-\mathrm{BAOx} \mathrm{x}_{15}\right)$ is enough the raise the $\mathrm{T}_{\mathrm{cp}}$ above body temperature upon addition of about $5 \mathrm{mM}$ of D-Glu, opening up the possibility of using this system for in vivo drug delivery applications. Similar to the $\mathrm{pH}$ titration, the effect of the added D-Glu is less for $\mathrm{P}\left(\mathrm{nPropO}_{91.5^{-}}\right.$ co-BAOx.5), with a maximum $\mathrm{T}_{\mathrm{cp}}$ of around $35{ }^{\circ} \mathrm{C}$ as a result of the lower amount of $\mathrm{BA}$ in the copolymers although it seems to reach this plateau value at the same D-Glu concentration as the $\mathrm{P}\left(\mathrm{nPropO} \mathrm{x}_{85}\right.$-co-BAOx $\left.{ }_{15}\right)$ namely around $75 \mathrm{mM}$. Limited sample availability precluded measurement of the transition temperatures of the $\mathrm{P}\left(\mathrm{nPropO}_{85}-\mathrm{Co}-\mathrm{BAO} \mathrm{x}_{15}\right)$ at the high glucose concentrations.

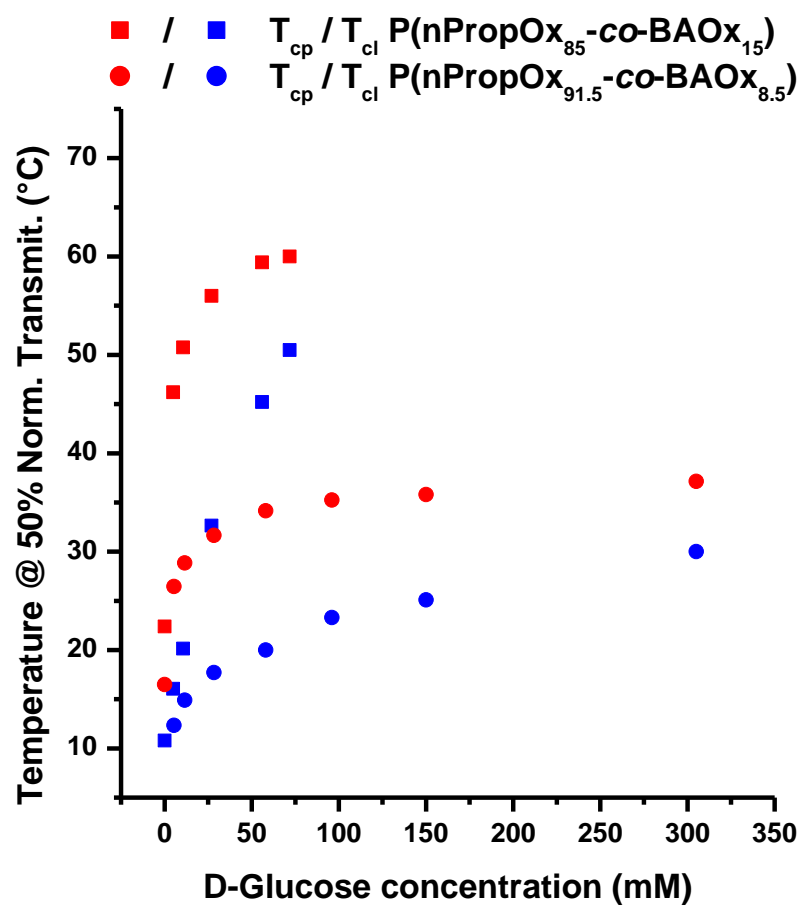

Figure 5. $T_{c p}$ (red) and $T_{c l}$ (blue) in function of added D-Glu concentration for a $1 \mathrm{mg} / \mathrm{mL}$ aqueous solution of $\mathrm{P}\left(\mathrm{nPropOx}_{85}-\mathrm{co}-\mathrm{BAOx_{15 } )}\right.$ (squares) and P(nPropO $x_{91.5}-$ co-BAO $_{8.5}$ ) (circles) buffered at $\mathrm{pH} 8.6$ with HEPES (0.1M).

The apparent increase in hysteresis in both cases as a result of the D-glucose concentration is unexpected and might be related to the identity of the BA moieties in the precipitated polymer. It is assumed that upon precipitation of the BA-polymer under these conditions, the glucose is not included within the formed polymer globule. The large hysteresis supports this idea as the exclusion of the glucose from the polymer globule would decrease the hydrophilicity and therefore both the $T_{c p}$ and 
$T_{c l}$. The gradual rehydration upon cooling results in a D-Glu concentration-dependent hysteresis as the more hydrated the polymer globule becomes, the more open the structure and the easier D-Glu can penetrate and bind. This observation may be controlled by careful polymer design, allowing a less dense structure upon precipitation by incorporating a fraction of a hydrophilic monomer like EtOx. The hysteresis, however, can also be used to the advantage of a possible in vivo insulin delivery system. If the current polymeric setup would be employed as a responsive semi-permeable gel of an insulin delivery device, for example, around body temperature $\left(\approx 37^{\circ} \mathrm{C}\right)$, a D-Glu concentration of $30 \mathrm{mM}$ would cause the gel to swell and release trapped insulin. Due to the large hysteresis however, the membrane will not close until the D-Glu concentration is below roughly $2 \mathrm{mM}$ ensuring the adequate uptake of glucose by the cells while preventing hypoglycemia. Alternatively, using a thermoresponsive BA-containing (co)polymer gel without hysteresis would keep the glucose level constant around a certain value. An added benefit to the large hysteresis and the steep increase of the $T_{c p}$ with D-Glu concentration is that the lower limit at which the polymeric gel would shrink and close is relatively stable and independent from the environmental temperature. Another potential of these polymerglucose systems with large hysteresis could be their use as visual read-out (clear or opaque solution) temperature sensors with thermal memory function, as was recently demonstrated for supramolecular thermoresponsive polymer systems with large hysteresis. ${ }^{59,60}$

\section{Conclusions and outlook}

The field of boronic-acid decorated copolymers was expanded with novel poly(2-alkyl-2-oxazolines), which were modified through the post-polymerization modification of a copolymer of $n$-propyl-2oxazoline (nPropOx) and a methyl ester oxazoline (MestOx). This biocompatible LCST copolymer can be modified with a variety of primary amines through direct amidation of the labile methyl ester. The use of ethylene diamine allowed the decoration of the PAOx copolymer with amines, which were subsequently modified with 4-carboxyphenylboronic acid using HATU-assisted amide formation. The 
addition of BA moieties alongside the PnPropOx introduces a $\mathrm{pH}$ and glucose dependency on the thermal transition characteristics, allowing control of the cloud and clearance point temperatures between 20 and $65{ }^{\circ} \mathrm{C}$. These novel triple-responsive materials are the first example of BAfunctionalized PAOx copolymers and highlight the potential of these materials in the fields of drug delivery, glucose-dependent permeable membranes or temperature sensors with thermal history.

\section{Acknowledgements}

GV acknowledges the Agency for Innovation by Science and Technology of Flanders (IWT) and the Research Foundation - Flanders (FWO) for funding. RH and MAM are grateful to BELSPO (IAP VII/5 Functional Supramolecular Systems FS2), FWO and UGent (BOF) for financial support. BSS acknowledges this material is partially based upon work supported by the National Science Foundation (DMR- 1606410). 


\section{References}

(1) Roy, D.; Cambre, J. N.; Sumerlin, B. S. Prog. Polym. Sci. 2010, 35 (1-2), 278.

(2) Schmaljohann, D. Adv. Drug Deliv. Rev. 2006, 58 (15), 1655.

(3) Bawa, P.; Pillay, V.; Choonara, Y. E.; du Toit, L. C. Biomed. Mater. 2009, 4 (2), 22001.

(4) Hall, D. G. Structure, Properties, and Preparation of Boronic Acid Derivatives. Overview of Their Reactions and Applications, Second, Co.; Hall, D. G., Ed.; WILEY-VCH Verlag GmbH \& Co. KGaA, 2006.

(5) Springsteen, G.; Wang, B. Tetrahedron 2002, 58 (26), 5291.

(6) Bromba, C.; Carrie, P.; Chui, J. K. W.; Fyles, T. M. Supramol. Chem. 2009, 21 (1-2), 81.

(7) Phillips, D.; Gibson, M. I. Polym. Chem. 2015, 6 (7), 1033.

(8) Zhao, Y. H.; Shantz, D. F. Langmuir 2011, 27 (23), 14554.

(9) Nakahata, M.; Mori, S.; Takashima, Y.; Hashidzume, A.; Yamaguchi, H.; Harada, A. ACS Macro Lett. 2014, 3 (4), 337.

(10) Brooks, W. L. A.; Sumerlin, B. S. Chem. Rev. 2016, 116 (3), 1375.

(11) Adhikari, B.; Majumdar, S. Prog. Polym. Sci. 2004, 29 (7), 699.

(12) Islam, M. R.; Gao, Y.; Li, X.; Zhang, Q. M.; Wei, M.; Serpe, M. J. Chinese Sci. Bull. 2014, 59 (32), 4237.

(13) Miyata, T.; Uragami, T.; Nakamae, K. Adv. Drug Deliv. Rev. 2002, 54 (1), 79.

(14) Roy, D.; Cambre, J. N.; Sumerlin, B. S. Chem. Commun. 2008, No. 21, 2477.

(15) Vancoillie, G.; Pelz, S.; Holder, E.; Hoogenboom, R. Polym. Chem. 2012, 3 (7), 1726.

(16) Matsumoto, A.; Yoshida, R.; Kataoka, K. Biomacromolecules 2004, 5 (3), 1038.

(17) Matsumoto, A.; Kurata, T.; Shiino, D.; Kataoka, K. Macromolecules 2004, 37 (4), 1502.

(18) Vancoillie, G.; Hoogenboom, R. Polym. Chem. 2016, DOI: 10.1039/C6PY00775A.

(19) Cambre, J. N.; Roy, D.; Gondi, S. R.; Sumerlin, B. S. J. Am. Chem. Soc. 2007, 129 (34), 10348.

(20) Cambre, J. N.; Roy, D.; Sumerlin, B. S. J. Polym. Sci. Part A Polym. Chem. 2012, 50 (16), 3373.

(21) Roy, D.; Sumerlin, B. S. ACS Macro Lett. 2012, 1 (5), 529.

(22) Li, Y.; Xiao, W.; Xiao, K.; Berti, L.; Luo, J.; Tseng, H. P.; Fung, G.; Lam, K. S. Angew. Chemie - Int. Ed. 2012, 51 (12), 2864.

(23) Liu, P.; Luo, Q.; Guan, Y.; Zhang, Y. Polymer 2010, 51 (12), 2668.

(24) Meng, H.; Xiao, P.; Gu, J.; Wen, X.; Xu, J.; Zhao, C.; Zhang, J.; Chen, T. Chem. Commun. 2014, 50 (82), 12277.

(25) Yang, H.; Sun, X.; Liu, G.; Ma, R.; Li, Z.; An, Y.; Shi, L. Soft Matter 2013, 9 (35), 8589.

(26) Naito, M.; Ishii, T.; Matsumoto, A.; Miyata, K.; Miyahara, Y.; Kataoka, K. Angew. Chemie - Int. Ed. 2012, 51 (43), 10751.

(27) Piest, M.; Zhang, X.; Trinidad, J.; Engbersen, J. F. J. Soft Matter 2011, 7 (23), 11111.

(28) Deshayes, S.; Cabral, H.; Ishii, T.; Miura, Y.; Kobayashi, S.; Yamashita, T.; Matsumoto, A.; Miyahara, Y.; Nishiyama, N.; Kataoka, K. J. Am. Chem. Soc. 2013, 135 (41), 15501.

(29) Preinerstorfer, B.; Lämmerhofer, M.; Lindner, W. J. Sep. Sci. 2009, 32 (10), 1673.

(30) Qin, Y.; Cheng, G.; Achara, O.; Parab, K.; Jäkle, F. Macromolecules 2004, 37 (19), 7123.

(31) Cui, C.; Bonder, E. M.; Qin, Y.; Jäkle, F. J. Polym. Sci. Part A Polym. Chem. 2010, 48 (11), 2438.

(32) Qin, Y.; Sukul, V.; Pagakos, D.; Cui, C.; Jäkle, F. Macromolecules 2005, 38 (22), 8987.

(33) Qin, Y.; Cheng, G.; Sundararaman, A.; Ja, F. J. Am. Chem. Soc. 2002, No. 124, 12672.

(34) Bauer, M.; Lautenschlaeger, C.; Kempe, K.; Tauhardt, L.; Schubert, U. S.; Fischer, D. Macromol. Biosci. 2012, 12 (7), 986.

(35) Sedlacek, O.; Monnery, B. D.; Filippov, S. K.; Hoogenboom, R.; Hruby, M. Macromol. Rapid Commun. 2012, 33 (19), 1648.

(36) Hoogenboom, R. Angew. Chemie - Int. Ed. 2009, 48 (43), 7978.

(37) Lava, K.; Verbraeken, B.; Hoogenboom, R. Eur. Polym. J. 2015, 65, 98.

(38) Wiesbrock, F.; Hoogenboom, R.; Leenen, M. A. M.; Meier, M. A. R.; Schubert, U. S. Macromolecules 2005, 38 (12), 5025. 
(39) Guillerm, B.; Monge, S.; Lapinte, V.; Robin, J.-J. Macromol. Rapid Commun. 2012, 33 (19), 1600.

(40) He, Z.; Miao, L.; Jordan, R.; S-manickam, D.; Luxenhofer, R.; Kabanov, A. V. Macromol. Biosci. 2015, 15 (7), 1004.

(41) Taubmann, C.; Luxenhofer, R.; Cesana, S.; Jordan, R. Macromol. Biosci. 2005, 5 (7), 603.

(42) Rinkenauer, A. C.; Tauhardt, L.; Wendler, F.; Kempe, K.; Gottschaldt, M.; Traeger, A.; Schubert, U. S. Macromol. Biosci. 2014, 15 (3), 414.

(43) Legros, C.; De Pauw-Gillet, M.; Tam, K. C.; Lecommandoux, S.; Taton, D. Eur. Polym. J. 2014, 62, 322.

(44) Nawroth, J. F.; Mcdaniel, J. R.; Chilkoti, A.; Jordan, R.; Luxenhofer, R. Macromol. Biosci. 2016, $16(3), 322$.

(45) Levy, A.; Litt, M. J. Polym. Sci. Part A-1 1968, 6 (7), 1883.

(46) Diehl, C.; Schlaad, H. Macromol. Biosci. 2009, 9 (2), 157.

(47) Mees, M. A.; Hoogenboom, R. Macromolecules 2015, 48 (11), 3531.

(48) Hoogenboom, R.; Thijs, H. M. L.; Jochems, M. J. H. C.; van Lankvelt, B. M.; Fijten, M. W. M.; Schubert, U. S. Chem. Commun. 2008, 44 (44), 5758.

(49) Park, J.; Kataoka, K. Macromolecules 2007, 40 (10), 3599.

(50) Zhang, N.; Luxenhofer, R.; Jordan, R. Macromol. Chem. Phys. 2012, 213 (18), 1963.

(51) Huber, S.; Jordan, R. Colloid Polym. Sci. 2008, 286 (4), 395.

(52) Hoogenboom, R.; Fijten, M. W. M.; Thijs, H. M. L.; van Lankvelt, B. M.; Schubert, U. S. Des. Monomers Polym. 2012, 8 (6), 659.

(53) Bouten, P. J. M.; Hertsen, D.; Vergaelen, M.; Monnery, B. D.; Boerman, M. A.; Goossens, H.; Catak, S.; van Hest, J. C. M.; Van Speybroeck, V.; Hoogenboom, R. Polym. Chem. 2015, 6 (4), 514.

(54) Bouten, P. J. M.; Hertsen, D.; Vergaelen, M.; Monnery, B. D.; Catak, S.; van Hest, J. C. M.; Van Speybroeck, V.; Hoogenboom, R. J. Polym. Sci. Part A Polym. Chem. 2015, 53 (22), 2649.

(55) Boerman, M. A.; Van der Laan, H. L.; Bender, J. C. M. E.; Hoogenboom, R.; Jansen, J. A.; Leeuwenburgh, S. C.; Van Hest, J. C. M. J. Polym. Sci. Part A Polym. Chem. 2016, 54 (11), 1573.

(56) Litt, M.; Levy, A.; Herz, J. J. Macromol. Sci. Part A - Chem. 1975, 9 (5), 703.

(57) Weber, C.; Hoogenboom, R.; Schubert, U. S. Prog. Polym. Sci. 2012, 37 (5), 686.

(58) Bloksma, M. M.; Bakker, J.; Weber, C.; Hoogenboom, R.; Schubert, U. S. Macromol. Rapid Commun. 2010, 31 (8), 724.

(59) de la Rosa, V. R.; Hoogenboom, R. Chem. Eur. J. 2015, 21 (3), 1302.

(60) Sambe, L.; de la Rosa, V. R.; Belal, K.; Stoffelbach, F.; Lyskawa, J.; Delattre, F.; Bria, M.; Cooke, G.; Hoogenboom, R.; Woisel, P. Angew. Chemie 2014, 53 (20), 5044. 